Uşak Üniversitesi Sosyal Bilimler Dergisi

2014, 7(1), 80-86

\title{
Yakut Türkçesinde Vasıta ve Ortaklık Hali
}

Mehtap SOLAK SAĞLAM

\section{Özet}

Türk dilinde kelime oluşumu kök ve ekler ile sağlanır. Ekler isim ve fiil köklerine eklenerek onlara tür ve görev anlamı kazandırmaktadır. Türkçede isimlerin, diğer kelimelerle ilişki kurarak cümlede görev kazanmasını sağlayan; isimleri isimlere, fiillere ve edatlara bağlayan ek ve yapılar "hâl" kavramı içinde değerlendirilmektedir. İsimleri vasıta haline getiren eke vasıta hali denir. Bu ek ismin instrumental şeklini yapar, ismi fiile bağlayarak vasıta ve zaman ifade etmesini sağlar. Ortaklık hali ise, eklendiği isme birliktelik anlamı katmaktadır. Çağdaş Türk lehçelerinde ortaklık ve vasıta hali aynı ek ya da kelime ile sağlanmaktadır. Bu iki hâl Çağdaş Türk lehçelerinde "birlen, bile, ile, menen" gibi yapılarla sağlanmakta, hem vasıta hem de ortaklık hâli bu şekilde oluşturulmaktadır. Yakut Türkçesi hâl kavramında farklılık göstermektedir. Ortaklık ve vasıta hali iki farklı yapı ile sağlanmaktadır. Ortaklık hâli için Yakut Türkçesinde +LIIn eki kullanılmaktadır. Bu ek kelimeye birliktelik anlamı verir. Yakut Türkçesinde vasıta hâline baktığımızda eski vasıta hâli eki "+n" ekini zarflarda ve zaman isimlerinde görmekteyiz. Bu ekin Yakut Türkçesindeki kullanım şekli +(I)nAn şeklindedir ve eklendiği kelimeye araç ilgisi katmaktadır. Yakut Türkçesinde vasıta ve ortaklık ekleri iki ayrı yapı olarak bulunur.

Anahtar Kelimeler: Ortaklık hali, vasıta hali, Yakut Türkçesi.

\section{Instrumental and Commitative Case In Yakut Turkish}

\section{Abstract}

Word formation in Turkish is conducted through roots and suffixes. Added to the noun and verb roots, suffixes give them typical and functional meanings. The suffixes and structures that help nouns relate to other words in the sentence and gain meaning and relate nouns to nouns, verbs and prepositions are evaluated in "case" concept. The suffix that makes nouns instruments is called instrumental case. This suffix, by relating it to verb, helps noun express instrument and time. Commitative case gives noun to which it is added the meaning of co-occurrence. In modern Turkic dialects,

${ }^{*}$ Dr. 
both cases are made with the same suffix or word. With structures "birlen, bile, ile, menen" both cases are made. Yakut Turkish is similar to Old Turkish in the cases. The commitative case and the instrumental case are made with two different structures. For the commitative case the suffix +LIIn is used in Yakut Turkish. This suffix gives the meaning of co-occurrence As to Yakut Turkish in terms of instrumental case, we see "+n", the old instrumental suffix, in adverbs and times. The Yakut Turkish version of this suffix is +(I)nAn and it gives the meaning of instrument to the word it is added. The commitative and instrumental suffix in Yakut Turkish exists as one same suffix.

Key Words: Commitative case, instrumental case, Yakut Turkısh.

Saha Cumhuriyeti, toprak büyüklüğü bakımından bugünkü bağımsız olan ve olmayan Türk Cumhuriyetlerinin en büyüğüdür. Bugün Rusya Federasyonu içerisinde $3.103 .200 \mathrm{~km}^{2}$ yüzölçümü ile Kuzeydoğu Sibirya'da, Kuzey Buz Denizi'ne dökülen Lena, Yana, İndigirka ve Kolıma ırmakları arasındaki havzada yer alır (Somuncuoğlu, 2002:120). Yakutistan bugünkü Rusya topraklarının \%18'ini kaplamaktadır. (Kirişçioğlu, 2002:134) Saha Türkleri, bu topraklarda daha ziyade hayvancilıkla uğraşarak geçimlerini sağlamaktadırlar (Seroşevski, 2007:64). Saha Türklerinin bugün yaşadıkları coğrafyaya göç etmeden önce Göktürk yazısını bildikleri, Sahaların tarihini ve milî kültürünü ortaya koyan olonholardan anlaşılmaktadır. Ayrıca arkeologların yaptığı araştırmalar neticesinde Lena ırmağı kıyısındaki mağaralarda Göktürk yazısına benzeyen yazılar bulunmuştur. Sahalar, Sibirya coğrafyasında yerleştikten sonra eski Türk yazı sistemi ve edebî geleneğini sürdürememişlerdir. 17. yüzyılda Saha ülkesini Rusların işgal etmeye başlamasıyla, Sahaları Hristiyanlaştırma çabaları da başlamış ve Saha topraklarında kiliseler kurulmuş ve dinî" metinler Saha Türkçesine çevrilmiştir. (Şirin User, 2006:164-165)

Saha Türkçesi, Çuvaş Türkçesiyle beraber ses değişiklikleri ve farklılıklar açısından incelendiğinde Türk lehçeleri arasında en farklı olan lehçedir. Saha Türkleri çok geniş bir coğrafyaya yayılmış olmalarına rağmen, sayısal olarak ele alındığında az bir nüfustur. Çoğunluğu Saha Cumhuriyeti'nde olmak üzere bu lehçeyi yaklaşık 456.000 kişi konuşmaktadır. Saha Türkçesi; Magadan, Sahalin bölgelerinde, Taymir ve Evenk özerk bölgelerinde de konuşulmaktadır. Sahaların dili aynı zamanda kuzey Sibirya küçük halklarının ticari dilidir. Bernard Comrie Sovyet toplumundaki dilleri incelediği eserinde, Saha Türkçesini, Dolganca ile beraber değerlendirmiş (zaman zaman farklı bir dil olduğunun düşünüldüğünü de belirterek), Türkçenin ana gövdesinden bilinmeyen bir 
zamanda ayrıldığını ve Tunguz etkisinde kaldığını söylemiş̧tir (Camrie, 1981:42). Saha Türkçesi, bünyesinde taşıdığı arkaik unsurlar bakımından, diğer Türk lehçe ve şiveleriyle karşılaştırıldığında oldukça zengindir. Saha Türkçesinin en belirgin özelliği aslî uzun ünlüleri yazı dilinde barındırmasıdır (Kirişçioğlu, 2002:134). Bunun dışında pek çok noktada Yakut Türkçesi, Eski Türkçe ile gerek söz varlığı açısından, gerekse ekler açısından paralellik göstermektedir.

Köktürkçe ve Saha Türkçesinin söz varllğı ve ekler olarak incelendiği müstakil eserler göz önüne alındığında şu sonuçlara ulaşılabilmektedir: Yakutçada ve Dolgancada devam eden sözcüklerin daha çok Orhon Türkçesindeki yalın ad ya da eylemler oldukları, türetilmiş ad ya da eylemlerin Yakutçada ve Dolgancada büyük ölçüde devam etmedikleri belirlenmiştir. Öte yandan Yakutçada ve Dolgancada devam eden sözcüklerin az bir bölümünün sesçe ya da anlamca hiçbir değişikliğe uğramadıkları, çok az bir bölümünün sesçe değişmediği hâlde farklı bir anlam kazandığı, büyük bir çoğunluğunun sesçe değişikliğe uğradığı hâlde anlamını koruduğu, yine az bir bölümünün hem sesçe hem anlamca değiştiği belirlenmiştir. Üç büyük yazıtta geçen 71 ekten Yakutçada ve Dolgancada devam edenlerin az bir bölümü sesçe hiçbir değişikliğe uğramadan günümüze kadar gelmiş, büyük bir çoğunluğu sesçe değişikliğe uğramıştır (Yıldız, 2007:131).

Türk dilinde kelime yapımı kök+yapım eki+çekim eki şeklindedir. İsimler aldıkları çekim ekleri ile cümlelerde çeşitli görevler üstlenirler. Hal ekleri, cümlenin anlamına tesir eden ve sık kullanılan isim çekim ekleridir. Bir cümlede geçen hal ekleri gerçek fonksiyonunda anlaşılmazsa, o cümleye verilen anlam da yanlış olur. (Gülsevin, 2007:16) Bir ismin, başka bir kelimeyle ilgi kurmak üzere aldığı eke "hâl eki" (ad durum eki) denir. Hâl ekleri, ismi kendisine tabi olmayan, kendisinin tabi olduğu unsurlarla ilgi kuran eklerdir (Gülensoy, 1995:45). Adların birbirleri ile veya fiiller ile ilişkisini belirleyen yapılar, belirli eklerle birleşerek aldıkları şekillerdir (Korkmaz, 2009:266).

Ortaklık ve vasıta hali bugün Türk lehçelerinde aynı ek ile sağlanmaktadır. +lA eki Türk lehçelerinde ortalık ve vasıta halini karşılamaktadır. Banguoğlu bu eki; isim çekimi başlığı altında, dışçekim halleri içinde değerlendirmektedir. Bu ekin "ile" takısından gelmekte olduğunu belirterek bu ekin eski şekil olan +In ekini iterek onun yerini aldığını belirtir. (adağın $\mathrm{X}$ ayakla) Bu iki ekin konuşma dilinde birleşerek gözlen, başlan, ayaklan, diziylen, korkuylan gibi örneklerde görüldüğüne değinmiştir (Banguoğlu, 1995:330). İsim çekimi için kullanılan "hâl" 
kavramına baktığımızda da Yakut Türkçesi ile Eski Türkçenin özellikle ortaklık hâli ve vasıta hâlinin iki farklı yapı ile karşılanıyor olması açısından benzerliği dikkat çekicidir.

\section{Vasıta Hâli (+(I)nAn)}

Bu hâl, adın belirttiği varlık veya nesnenin fiildeki oluş ve kılışta "vasıta" olarak kullanıldığını veya "birliktelik" ifade ettiğini gösterme durumudur (Korkmaz, 2009:317).

Türkçedeki eski vasıta hâli eki -n'dır. $+n$; +1n, +in; $n$ ağzında bazen +an, +än ve yuvarlak ünlülerden sonra zaman zaman +un, +ün olur (Gabain, 1995:64):

yadag்+(1)n "yayan"; bärgä+n "kamış, çubuk ile"; küri+n.

arı̀+ın "orman ile"; öz+in "kendi ile"; ot+ın "ateş ile"

öd+ün "zaman ile"; ögrünç+ün "sevinç ile"

tamir+än "demir ile".

Ek bugün kullanımdan düşmüş fakat bazı sözcüklerde kalıplaşmış olarak varlığını korumaktadır. (yayan, öğlen, ilkin vb.) Bu ek Yakut Türkçesinde de zarflarda ve zaman isimlerinde yaşamaktadır: kıhın "kışın". Vasıta hali " $+n$ " eki Eski ve Orta Türkçe, Eski Anadolu Türkçesi dönemlerinde kullanıldıktan sonra, Osmanlıca döneminde kullanımdan düşmüştür. Eski Anadolu Türkçesinde asıl vasıta hali eki $+n$ ve yanında +la, birle, ile şekilleri de kullanılmıştır. $+n$ eki kullanımdan düşünce onun yerini ile edatı almıştır. Türkiye Türkçesinde "ile" son çekim edatı ve onun ekleşmiş +la/+le şekilleri kullanılmaktadır (İpek, 2012:23).

Yakut (Saha) Türkçesindeki yeni şekil -(I)nAn (özel isimlerde -lan/len) ise, -lan şeklinden gelmektedir. Bu şeklin ile edatının -n vasıta hâli ekiyle birleşmesinden ortaya çıtığı bellidir (Kiriş̧̧ioğlu, 2007:1259). Ekin Saha Türkçesindeki kullanım şekli +(I)nAn şeklindedir, eklendiği kelimeye araç ilgisi ve birliktelik anlamı kurar: örükütebin.

... siri-doydunu küöx ï̈̈neeyinen çelgitebin, kırılas kumağınan

“... yeryüzünü yeşil bitkilerle kaplarım, hışırtılı kum ile kabartırım.”

Bu kıhı kergen ılbıt kihi kötör aalınan köñül kötüöxteex uonna, bıyañnaax caahıginan tuhanan, uygutuk oloruoxtaax.

"Bu kızı aile (eş) alan kişi, uçan salı ile serbestçe uçacak ve zengin sandığından yararlanacak, bolluk içinde yaşayacakmış."

...saxa kihite sataan sabağalaabat aatınan aattaarı̃̃ uonna kini aatın taba taaybut kimiexe da eteeğeybit.

“... Saha insanlarının tahmin edemeyeceği (bir) ad ile adlandırsın ve o adı kimseye söylemesin." 
Anı xañas iliitinen strbatar. Illiite emie sıstar. Ataxtarnan teppite, sinbiir ol kurduk, sıstan xaalallar. Kelin uhugar baha ordor. "Biligin sinim biir, kıayan kuoppappin",-dii sanaat, sü̈̈hünen saayar.

"Sonra diğer eli ile vurdu. Eli de yapışmış. Ayakları ile tekme atmış, onlar da yapışmış. Sonunda sadece kafası kalmış. "Şimdi nasılsa kaçamam" diye düşünüp, kafası ile vurdu."

Emie xahıñtan xarıstaabıttar, kuraantan xorğopputtar, kölöhünnerinen ibiirbitter, xaraxtarın uutunan ağaabıttar, tıınnarınan silıppıttar.

"Yine dondan korumuşlar, kuraklıktan saklamışlar, terleri ile sulamışlar, gözlerinin yaşı ile ıslatmışlar, ruhları ile ısıtmışlar."

\section{Ortaklık Hâli (+LIIn)}

Ortaklık hali çağdaş Türkçenin morfolojisi için bir standart değildir. Yakutça ve Dolgancada bu ekin farklı kullanım şekilleri bulunmaktadır. (Comit+acc, comit.+dat., comit.+abl., comit+instr.) bu yapılar eklendikleri kelimelere farklı görevler kazandırmaktadır (Stachowski, 1995:555).

Saha Türkçesinde özel bir hâl olan "ortaklık" genellikle Batı Avrupa dillerinde bulunur. Bu hal herhangi bir şeyi, bir şahıs veya grupla yapmayı belirtir. Bu ekin kökeni hakkında Eski Türkçe dönemine dayanan iki görüş bulunmaktadır.: İlk görüş, ekin ET. +lıg>+lı ekine vasita hal eki $+n$ eklenmesiyle; ikinci görüş ise ET.+li.....+li ekine vasıta hali eki +n'nin eklenmesi yoluyla oluştuğu şeklindedir (Kirişçioğlu, 1999:77).

Ortaklık anlamı +LIIn eki ile sağlanır. Bu ekin Saha Türkçesindeki ses değişmelerine bağlı olarak 16 farklı varyantı bulunmaktadır: +lın, +liin, +luun, +lüün, +tın, +tuun, +tüün, +nın, +nuun, +nüün, +dın, +diin, +duun, +düün (Ubryatova, 1995:73). Kruger Bu ek için "Sociative case" adını kullanarak, yüklemde belirtilen işin bir topluluk tarafından yapıldığını belirttiğini söyler (Kruger, 1962:86-88). Bu ek kelimeye birliktelik anlamı verir. (Stachowskı, 1995:558) Bu hâl, sadece Saha Türkçesinde ayrı bir ek ile sağlanmaktadır. Diğer lehçelerde ortaklık ve vasıta hâli aynıdır. (birlen/bile/ile/menen) (Pakendorf, 2007:197)

Otton Colloox Corğoot Aalı-kuoluun xolbohon zal buolbuttar, olox olorbuttar, oğo töröppütter, collorun bulbuttar.

"Sonra Talihli Yiğit, Aalı kuo ile birleşip aile olmuşlar, uzun yaşamışlar, oğulları olmuş, saadetlerini bulmuşlar."

Tañastıın-saptıı, etiin-siinniin, battaxtıın, kılamannıın-bartta kıhıl kömüs .

“Elbisesi ile, ipi ile, vücudu ile, bedeni ile, saçı ile, kirpiği ile her yeri altınmış." 
Manñattıın, kutuu uonna kumax kömüstüün ikki at tardıta buolsu,diebit Tiiñey.

"Para ile, dökme ve kum gümüş ile iki at yükü olsun, demiş Tiiñey."

Bă̆atının ikkien cieleriger tağıstılar.

"Kurbağası ile ikisi evlerine çıktılar."

Suorğannuın-tellextiin barıta sitıyda.

"Yorgan ile, örtüyle hepsi 1slandı."

Sonuç olarak kelime oluşumunun kök ve eklerle sağlandığı Türk dilinde isimleri isimlere, fiiller ve edatlara bağlayan ek ve yapılar "hal" olarak nitelendirilmektedir. Vasıta ve ortaklık hâlinin Türk dilinde aynı ekle sağlandığı görülmektedir. Örnekler üzerinde gösterildiği üzere Yakut Türkçesi bu iki hâli iki farklı ekle sağlamaktadır.

\section{Kaynakça}

Banguoğlu T. (1995) Türkçenin Grameri, Ankara: TDK Yayınları.

Camrie B. (1981) The Languages of The Soviet Union, Cambridge: Cambridge Language Surveys.

Gabain A. V.(1995) Eski Türkçenin Grameri, Ankara: TDK Yayınları.

Gülsevin G. (2007) Eski Anadolu Türkçesinde Ekler, Ankara: TDK Yayınları.

İpek B. (ET.30.11.2012) Türk Dilinde Vasıta Hali, www.turkiyat.selcuk. edu.tr/pdfdergi/s23/ipek.pdf.

Kirişçioğlu M. F. (2007). Saha Türkçesi, Türk Lehçeleri Grameri (Editör: A. Bican Ercilasun), Ankara: Akçağ Yayınları.

Kirişçioğlu M. F. (2002), Sahalar (Yakutlar) ve Saha Türkçesi, Türkler Ansiklopedisi, C.20, Ankara: Yeni Türkiye Yayınları. s: 133-140

Kirişçioğlu M. F. (1999), Saha (Yakut) Türkçesi Grameri, Ankara: TDK Yayınları.

Korkmaz Z. (2009) Türkiye Türkçesi Grameri Şekil Bilgisi, Ankara: TDK Yayınları.

Kruger J. (1962) Yakut Manual, Bloomington: Indiana Unıversity Publications, Uralıc Altaıc Series vol.21.

Pakendorf B. (2007) Contact in Prehistory of The Sakha (Yakuts): Linguistic and Genetic Perspectives, Utrect: LOT Dissertation Series 170. 
Seroşevski V.L. (2007). Saka Yakutlar, İstanbul: Selenge Yayıncılık.

Somuncuoğlu A. (2002) Saha Cumhuriyeti, Türkler Ansiklopedisi C.20, Ankara: Yeni Türkiye Yayınları. s: 119-131.

Stachowskı M. (1995) Der Komitativ im Jakutischen und Dolganischen, Analecta Indoeuropaea Cracoviensia vol.II, Krokow: Cracow Universitas. s: 553-559.

Ubryatova E.İ. (1995) Grammatika Sovremennogo Yakutskogo Literaturnogo Yazıka, Novosibirsk: Sibirskaya İzdatelskaya Firma ran, Nauka.

Şirin User H. (2006) Başlangıçtan Günümüze Türk Yazı Sistemleri, Ankara: Akçağ Yayınları.

Yıldız H. (2007) Orhon Türkçesi ile Yakutçanın Sözvarliğı ve Sözyapımı Bakımından Karşılaştııılması, Anadolu Üniversitesi Sosyal Bilimler Enstitüsü, Yayımlanmamış Yüksek Lisans Tezi, Eskişehir. 